\title{
PENERAPAN STRATEGI PEMECAHAN MASALAH WANKAT- OREOVOCZ DALAM PENINGKATAN LITERASI MATEMATIS SISWA SMP DITINJAU DARI PENGETAHUAN AWAL MATEMATIS (PAM) SISWA
}

\author{
Nego Linuhung \\ Pendidikan Matematika FKIP Universitas Muhammadiyah Metro \\ E-mail: nego_mtk@yahoo.co.id
}

\begin{abstract}
The aim of this research to analyze the essence of learning the strategy of WankatOreovocz problem solving as alternative the problem solution. The research design which is used is a non-equivalent control group design by using technique of Purposive Sampling. The Research Subject is all eight grade students of Sukahaji Junior High School with the research sample is VIIIG grade students. The research instrument used in the form is prior mathematical knowledge test (PAM), mathematical literacy test of level 5. Result of the research indicates that: 1) There is the difference of mathematical literacy improvement of level 5 at student who is getting The Strategy of Wankat-Oreovocz Problem Solving (WO) evaluated from the PAM student category (high and low).
\end{abstract}

Keywords: Mathematical Literacy Level 5, The Strategy of Wankat-Oreovocz Problem Solving

\section{PENDAHULUAN}

Dalam kurikulum tingkat satuan pendidikan (Depdiknas, 2006), mata pelajaran matematika perlu diberikan kepada semua peserta didik mulai dari sekolah dasar untuk membekali peserta didik dengan kemampuan berpikir logis, analitis, sistematis, kritis, dan kreatif, serta kemampuan bekerjasama. Kompetensi tersebut diperlukan agar peserta didik dapat memiliki kemampuan memperoleh, mengelola, dan memanfaatkan informasi untuk bertahan hidup pada keadaan yang selalu berubah, tidak pasti, dan kompetitif.

Ojose (2011:90) literasi matematis adalah pengetahuan untuk mengetahui dan menerapkan matematika dasar pada kehidupan sehari-hari, namun berbagai penulis telah menempatkan literasi matematika sebagai "melek" matematis. Literasi matematika melibatkan pengetahuan, kompetensi dan kepercayaan diri untuk menerapkan pengetahuan ini dalam dunia praktis. Seseorang dapat dikatakan melek matematis 
apabila dapat memperkirakan, menafsirkan data, memecahkan masalah sehari- hari. Guru harus mengajar sedemikian rupa agar pemahaman konseptual diperoleh oleh siswa. Ini adalah satusatunya cara mereka akan mampu menerapkan belajar matematika dalam kehidupan nyata. Selain itu, konten yang diajarkan di sekolah harus mencerminkan relevansi dengan masyarakat.

Pada kenyataannya di lapangan, strategi pembelajaran yang dilakukan guru juga tidak banyak melatih siswa mencapai tujuan pendidikan pada level tertinggi. Turmudi (2010: 7) yang menyatakan bahwa pembelajaran matematika selama ini disampaikan kepada siswa secara informatif, artinya siswa hanya memperoleh informasi dari guru saja, sehingga derajat "kemelekatannya" juga sangat rendah, akibatnya siswa cepat lupa dan akibat lanjutannya adalah rendahnya hasil pencapaian siswa.

Guru seharusnya dapat menggunakan strategi yang tepat untuk membantu siswa meningkatkan literasi matematis agar dapat menyelesaikan persoalan-persoalan kehidupan sehari-hari. Siswa harus mampu menganalisis, memberi alasan dan mengkomunikasikan pengetahuan dan keterampilan matematikanya secara efektif, serta mampu memecahkan dan menginterpretasikan permasalahan matematika dalam berbagai situasi seperti halnya soal-soal yang diberikan dalam PISA disajikan dalam konteks dunia nyata, sehingga dapat langsung dirasakan manfaat matematika dalam memecahkan permasalahan kehidupan seharihari.

$\begin{array}{lr}\text { Wankat dan } & \text { Oreovocz } \\ \text { (dalam Wena, } & 2009) \\ \text { mengemukakan tahap-tahap } \\ \text { strategi operasional } & \text { dalam } \\ \text { pemecahan masalah sebagai } \\ \text { berikut: }\end{array}$

1. Saya mampu/bisa (I can);

Tahap membangkitkan motivasi dan membangun/menumbuhkan keyakinan siswa.

2. Mendefinisikan (Define); Membuat daftar hal yang diketahui dan tidak diketahui, menggunakan gambar grafis untuk memperjelas permasalahan.

3. Mengeksplorasi (Explore); Merancang siswa untuk mengajukan pertanyaan-pertanyaan dan membimbing untuk menganalisis dimensi-dimensi permasalahan yang dihadapi.

4. Merencanakan (Plan);

Mengembangkan cara berpikir logis untuk menganalisis masalah dan menggunakan flowchart untuk menggambarkan masalah-masalah yang dihadapi. 
5. Mengerjakan (Do it); Membimbing siswa secara sistematis memperkirakan jawaban yang mungkin untuk memecahkan masalah yang dihadapi.

6. Mengoreksi kembali (Check); Membimbing siswa untuk mengecek kembali jawaban yang dibuat, mungkin ada beberapa kesalahan yang dilakukan, dan

7. Generalisasi (Generalize).

Membimbing siswa mengajukan pertanyaan: apa yang telah saya pelajari dalam pokok bahasan ini? Bagaimanakah agar pemecahan masalah yang dilakukan lebih efisien? Jika pemecahan masalah yang dilakukan masih kurang benar, apa yang harus saya lakukan? dalam hal ini dorong siswa melakukan umpan balik/refleksi dan mengoreksi kembali kesalahan yang mungkin ada. Pengetahuan awal matematika (PAM) siswa merupakan aspek yang akan ditinjau dan menjadi fokus penelitian ini selain dari aspek pembelajaran dan aspek psikologis. Level PAM siswa di kelas sangat beragam, hal ini menjadi pertanyaan bagaimana metode pembelajaran yang diberikan guru dapat berpengaruh atau tidak pada level pengetahuan. Peneliti menduga siswa berkemampuan tinggi akan dapat meningkat hasil belajarnya dengan menggunakan metode pembelajaran apapun, namun hal sebaliknya terjadi pada siswa berkemampuan rendah, sehingga dalam penelitian ini akan melihat bagaimana PAM siswa berpengaruh terhadap metode pembelajaran yang akan diberikan terhadap literasi matematis. Tujuannya yaitu untuk melihat apakah implementasi pembelajaran yang digunakan dapat merata di kategori PAM siswa atau hanya kategori PAM tertentu saja. Jika merata di semua kategori PAM, maka penelitian ini dapat digeneralisir bahwa implementasi pembelajaran yang digunakan cocok diterapkan untuk semua level kemampuan ataupun jika tidak merata di semua PAM maka kategori manakah yang cocok untuk implementasi pembelajaran ini.

Pada penelitian ini literasi matematis yang diukur adalah literasi matematis level 5. Pada level ini kemampuan yang diukur yaitu siswa dapat bekerja dengan model untuk situasi yang kompleks, mengidentifikasi kendala yang dihadapi dan melakukan dugaan-dugaan. Siswa dapat memilih, membandingkan, dan mengevaluasi sesuai dengan strategi pemecahan masalah dalam menghadapi masalahmasalah kompleks yang berhubungan dengan model tersebut. 
Selanjutnya, penelitian ini bertujuan untuk menelaah perbedaan peningkatan literasi matematis level 5 pada siswa yang mendapat pembelajaran dengan strategi pemecahan masalah Wankat-Oreovocz ditinjau dari kategori PAM siswa.

\section{METODE PENELITIAN}

Metode penelitian yang akan digunakan dalam penelitian ini adalah metode penelitian eksperimen. Ruseffendi (2005) mengungkapkan bahwa pada kuasi eksperimen ini subjek tidak diacak tetapi peneliti menerima keadaan subjek apa adanya. Desain penelitian yang digunakan adalah desain kelompok kontrol non-ekivalen. Subyek dalam penelitian ini meliputi seluruh siswa kelas VIII SMP N 1 Sukahaji semester 2 tahun pelajaran 2012/2013. Sampel penelitiannya adalah kelas VIIIG sebanyak 31 siswa.

Siswa dikelompokkan ke dalam dua kategori, yaitu siswa kategori PAM atas dan siswa kategori PAM bawah. Siswa hanya dibagi menjadi dua kategori karena untuk mengantisipasi terganggunya uji normalitas dan homogenitas akibat dari jumlah sampel yang terlalu kecil.

Adapun kriteria pengelompokan sebagai berikut:
Tabel 1. KriterianPengelompokkan PAM Siswa

\begin{tabular}{|l|l|}
\hline Skor PAM & $\begin{array}{l}\text { Kategori PAM } \\
\text { Siswa }\end{array}$ \\
\hline PAM $\geq \bar{x}$ & $\begin{array}{l}\text { Siswa kategori } \\
\text { atas }\end{array}$ \\
\hline PAM $<\bar{x}$ & $\begin{array}{l}\text { Siswa kategori } \\
\text { bawah }\end{array}$ \\
\hline
\end{tabular}

Hasil pengklasifikasian didiskusikan bersama guru matematika, sehingga diperoleh data siswa kategori PAM yaitu banyaknya siswa pada kategori PAM Atas adalah 16 siswa dan banyaknya siswa pada kategori PAM bawah adalah 15 siswa.

\section{HASIL PENELITIAN DAN PEMBAHASAN}

Deskripsi rataan $\mathrm{N}$-gain dan standar deviasi data literasi matematis level 5 siswa berdasarkan kategori PAM disajikan tabel berikut:

Tabel 2. Perbandingan Selisih antar Kategori PAM

\begin{tabular}{|l|l|l|}
\hline \multirow{2}{*}{$\begin{array}{l}\text { Kategori } \\
\text { PAM }\end{array}$} & \multicolumn{2}{|l|}{ Pembelajaran WO } \\
\cline { 2 - 3 } & $\begin{array}{l}\text { Rataan } \\
\text { N-gain }\end{array}$ & $\begin{array}{l}\text { Std. } \\
\text { deviasi }\end{array}$ \\
\hline Atas & 0,4900 & 0,13079 \\
\hline Bawah & 0,3747 & 0,11630 \\
\hline Beda rataan & 0,1153 & \\
\hline
\end{tabular}

Dari Tabel 2 di atas terlihat bahwa siswa kategori PAM atas memiliki rataan skor $\mathrm{N}$-gain yang lebih besar dari pada siswa kategori PAM bawah. rataan skor $\mathrm{N}$-gain siswa kategori 
PAM atas sebesar 0,49 dan siswa kategori PAM bawah sebesar 0,3747 .

Berdasarkan hasil uji normalitas dan uji homogenitas yang telah dilakukan sebelumnya didapat kesimpulan bahwa skor $\mathrm{N}$-gain kategori PAM atas dan siswa kategori PAM bawah berdistribusi normal berasal dari varian yang homogen. Setelah diketahui bahwa data skor N-gain memenuhi uji prasyarat kenormalan dan homogenitas.

Uji perbedaan rataan $\mathrm{N}$ gain dengan menggunakan Independent Sample t-test dengan bantuan program SPSS 16.

Tabel 3. Uji Perbedaan Rataan Skor N-gain

\begin{tabular}{|l|l|l|l|}
\hline $\begin{array}{l}\text { Kategori } \\
\text { PAM }\end{array}$ & $\begin{array}{l}\text { Perbedaan } \\
\text { Rataan }\end{array}$ & Sig. & $\begin{array}{l}\text { Keput } \\
\text { usan }\end{array}$ \\
\hline $\begin{array}{l}\text { Atas }>< \\
\text { Bawah }\end{array}$ & 0,1153 & 0,015 & $\begin{array}{l}\mathrm{H}_{0} \\
\text { Ditolak }\end{array}$ \\
\hline
\end{tabular}

Pada Tabel 3 terlihat nilai signifikansi untuk pasangan PAM atas dan bawah adalah 0,015 lebih kecil dari $\alpha=0,05$, ini berarti skor N-gain literasi matematis level 5 siswa yang berada pada kategori PAM atas secara signifikan berbeda dari skor Ngain literasi matematis level 5 siswa kategori PAM bawah.

Pengetahuan awal matematika siswa dalam penelitian ini, digunakan untuk mengelompokkan siswa menjadi dua kategori yaitu siswa berkemampuan atas dan bawah. Klasifikasi ini didasarkan pada hasil tes PAM siswa yang diberikan, serta hasil pengklasifikasian oleh peneliti di kelas tersebut. Berdasarkan hasil penelitian, PAM siswa memberikan pengaruh terhadap literasi matematis level 5 siswa.

\section{KESIMPULAN DAN SARAN}

Berdasarkan hasil penelitian dan pembahasan diperoleh kesimpulan bahwa: terdapat perbedaan peningkatan literasi matematis level 5 siswa yang mendapat pembelajaran strategi pemecahan masalah Wankat-Oreovocz pada siswa kategori PAM atas dengan siswa kategori PAM bawah, sehingga ini menunjukkan bahwa pada siswa kategori PAM atas peningkatan kemampuannya lebih tinggi dibandingkan dengan siswa kategori PAM bawah.

Berdasarkan kesimpulan penelitian di atas, diajukan beberapa saran yaitu:

1. Pembelajaran dengan strategi pemecahan masalah WankatOreovocz (WO) hendaknya menjadi alternatif pembelajaran sebagai implementasi dari pengembangan pembelajaran matematika khususnya dalam meningkatkan literasi matematis level 5.

2. Pada penelitian ini dilakukan pada kategori PAM atas dan bawah saja, sehingga perlu dilakukan penelitian lanjutan pada kategori PAM atas, sedang 
dan bawah untuk mengetahui bagaimana pengaruh pembelajaran dengan strategi pemecahan masalah WankatOreovocz (WO) terhadap literasi matematis level 5.

\section{DAFTAR PUSTAKA}

Depdiknas. 2006. Kurikulum 2006 Mata Pelajaran Matematika SMP/MTs. Jakarta: Departemen Pendidikan Nasional.

Ojose. B. (2011). Mathematics Literacy: Are We Able To Put The Mathematics We Learn Into Everyday Use?. Journal of mathematics Education. June 2011, vol. 4, no 1, pp.89-100. U.S.A: University of Redlands

Ruseffendi, E.T. 2005. Dasar-

Dasar Penelitian

Pendidikan dan Bidang Non-Eksakta Lainnya. Bandung: Tarsito

Turmudi. 2010. Matematika Eksploratif dan Investigatif; Referensi Metodologi Pembelajaran untuk Guru Matematika. Jakarta: Leuser Cita Pustaka.

Wena, M. 2009. Strategi Pembelajaran Inovatif Kontemporer Suatu Tinjauan Operasional. Jakarta: Bumi Aksara. 